\title{
Effect of short-term feeding of genetically modified Bt maize (MON810) on gut microbiota, intestinal morphology and immune status of weanling pigs
}

\author{
M.C. Walsh ${ }^{1}$, S.G. Buzoianu ${ }^{1,2}$, G.E. Gardiner ${ }^{2}$, M.C. Rea ${ }^{3}$, O.M. Hart ${ }^{4}$, P. Ross ${ }^{3,5}$, P.G. Lawlor ${ }^{1}$
}

${ }^{1}$ Teagasc Pig Production Development Unit, Moorepark Research Centre, Fermoy, Co. Cork, Ireland, ${ }^{2}$ Waterford Institute of Technology, Waterford, Ireland, ${ }^{3}$ Teagasc, Moorepark Research Centre, Fermoy, Co. Cork, Ireland, ${ }^{4}$ Eli Lilly, Greenfield, Indianapolis, United States, ${ }^{5}$ Alimentary Pharmabiotic Centre, Cork, Ireland

Email: maria.walsh@teagasc.ie

Introduction The inclusion of genetically modified (GM) plants in animal feed and for human consumption has consistently increased over the past thirteen years since they were first cultivated in 1996 (Schnepf et al., 1998). Since the introduction of GM crops much debate, has centred around issues relating to their safety for consumption. Consumer concerns are mostly related to a perceived risk to health, allergenicity of the transgenic proteins or the transfer of antibiotic resistance from the plant to bacteria residing in the human gastrointestinal tract (Bertoni and Marsan, 2005). The objective of the current study was to identify any effects that short-term feeding of transgenic MON810 maize may have on gut microbiota, intestinal morphology and immune status of weanling pigs.

Materials and methods Crossbred weanling pigs (entire males; $n=32$ ) were used in a 36 day experiment. Pigs were weaned at $\sim 28 \mathrm{~d}$ of age, blocked by weight and ancestry, and randomly assigned to one of two treatments. Pigs were housed individually in a total of 4 rooms with 8 pigs per room (16 pigs/treatment). Diets were non-medicated weanling diets and experimental treatments were as follows; diet 1 - Non-GM isogenic parent line of maize and diet 2 - transgenic MON810 maize. Faecal samples were taken from 32 pigs $(n=16$ pigs/treatment $)$ before $(d-1)$ and at the end of feeding experimental treatments (d 30) for microbiological analysis. On d 31, 10 pigs/treatment were slaughtered by captive bolt stunning followed by exsanguination. Immediately post-mortem terminal ileal and cecal digesta were collected from 10 pigs/treatment for microbiological analysis. Tissue samples were also taken from the small intestine for the determination of gross morphology. Whole blood samples were taken from 10 pigs/treatment on d 0, and 29. Peripheral blood mononuclear cells (PBMCs) were isolated from whole blood, stimulated with the mitogen phorbol myristate acetate (PMA) and cytokine production by the cells measured by ELISA. All data was analyzed as a complete randomised block design using the GLM procedures of SAS (SAS Inst. Inc., Cary, NC). For all response criteria, an individual pig was the experimental unit. Microbiology data were log-transformed prior to analysis to ensure data points were normally distributed.

Results To identify if transgenic MON810 maize consumption had an influence on culturable faecal or intestinal microbial populations, total Lactobacillus, Enterobacteriaceae and total anaerobes were enumerated. The effect of short-term feeding of MON810 maize on gut microbiota is shown in Table 1. Short-term feeding of transgenic MON810 maize to weanling pigs had no effect on duodenal, jejunal or ileal villus height, crypt depth, villus height:crypt depth ratio or number of goblet cells/villus in the duodenum, jejunum and ileum. However, non-GM fed pigs tended ( $\mathrm{P}=0.10)$ to have more goblets cells/ $\mu \mathrm{m}$ of duodenal villus compared to GM fed pigs. To assess the effects of short-term feeding of transgenic MON810 maize on the systemic immune response, cytokine production by PBMCs was measured following mitogen stimulation. Mitogen stimulated PBMCs isolated from pigs fed transgenic MON810 on d 30 tended to produce less IL-12 than cells isolated from control pigs at the same timepoint $(312.7$ vs $1321 \mathrm{pg} / \mathrm{mL} ; \mathrm{P}<0.09)$. There was no effect of treatment on IL-10, IL-6, IL-4 or TNF $\alpha$ production either from resting or stimulated PBMCs.

Table 1 The effects of short-term feeding of MON810 maize on gut microbiota

\begin{tabular}{|c|c|c|c|c|}
\hline & Non-GM maize & GM maize & SE & P-value \\
\hline Fecal Enterobacteriaceae - d 0, $\log _{10} \mathrm{CFU} / \mathrm{g}$ & 7.96 & 7.80 & 0.071 & 0.182 \\
\hline Fecal Enterobacteriaceae - d 30, $\log _{10} \mathrm{CFU} / \mathrm{g}$ & 7.05 & 6.37 & 0.290 & 0.105 \\
\hline Fecal Lactobacillus $-\mathrm{d} 30, \log _{10} \mathrm{CFU} / \mathrm{g}$ & 9.02 & 9.41 & 0.146 & 0.106 \\
\hline Fecal Total Anaerobes- d $0, \log _{10} \mathrm{CFU} / \mathrm{g}$ & 9.39 & 9.48 & 0.072 & 0.395 \\
\hline Fecal Total Anaerobes - d 30, $\log _{10}$ CFU/g & 9.26 & 9.26 & 0.111 & 0.980 \\
\hline Ileal Enterobacteriaceae - d 31, $\log _{10} \mathrm{CFU} / \mathrm{g}$ & 5.61 & 5.80 & 0.387 & 0.749 \\
\hline Ileal Lactobacillus $-\mathrm{d} 31, \log _{10} \mathrm{CFU} / \mathrm{g}$ & 6.21 & 6.31 & 0.117 & 0.574 \\
\hline Ileal Total Anaerobes - d 31, $\log _{10} \mathrm{CFU} / \mathrm{g}$ & 7.18 & 6.99 & 0.214 & 0.556 \\
\hline Cecal Enterobacteriaceae - d 31, $\log _{10} \mathrm{CFU} / \mathrm{g}$ & 6.31 & 6.65 & 0.194 & 0.261 \\
\hline Cecal Lactobacillus - d 31, $\log _{10}$ CFU/g & 7.78 & 7.91 & 0.152 & 0.574 \\
\hline Cecal Total Anaerobes - d 31, $\log _{10} \mathrm{CFU} / \mathrm{g}$ & 9.29 & 9.38 & 0.101 & 0.568 \\
\hline
\end{tabular}

Conclusions Results obtained from short-term feeding of transgenic MON810 maize to weanling pigs have demonstrated no adverse effects on intestinal morphology, no changes in selected culturable gastrointestinal microbial populations with the exception of a trend for reducing a potentially pathogenic population in the faeces, and a lack of systemic immune stimulation. Overall, to date we have found that transgenic MON810 maize has failed to adversely alter the physiology of the weaned pig in any parameter measured; however continued research in this area will provide more definitive answers.

Acknowledgements The authors gratefully acknowledge funding from the EU Commission $7^{\text {th }}$ Framework Programme

\section{References}

Bertoni, G., and Marsan, P.A. 2005. Veterinary Research Communications Suppl. 2, 13-18.

SAS. 2000. SAS User's Guide: Statistics. SAS Institute, INC., Cary, NC.

Schnepf, E. Crickmore N., Van Rie J., et al. 1998. Microbiology and Molecular Biology Reviews 62, 775-806. 